\title{
A COMPARATIVE STUDY ON PHARMACOECONOMIC ANALYSIS OF RHEUMATOID ARTHRITIS PATIENT IN TWO DIFFERENT HOSPITALS IN TAMIL NADU
}

\author{
ARUL PRAKASAM K. C. , ATHMAJA KRISHNA P. S., ALEENA S., ASLAM A., MARIA JOY
}

JKKMMRF'S Annai JKK Sampoorani Ammal College of Pharmacy B. Komarapalayam 638183, Namakkal Dt, TamilNadu Email: kcarul2000@gmail.com

Received: 22 Oct 2019, Revised and Accepted: 01 Jan 2020

\begin{abstract}
Objective: The objective of the present study is to compare the prescribing patterns and cost of illness of Rheumatoid arthritis patients in two different hospitals.
\end{abstract}

Methods: This is an observational study conducted in two different tertiary care hospitals in Salem district after obtaining approval of the Institutional Ethics Committee (IEC) (Registration Number EC/PHARM D/2019.06). A sample size of 102 (above 18 y) patients were included (52 from group 1 hospital and 50 from group 2 hospital). The study was conducted over a period of 6 mo from February 2019 to July 2019. The cost was collected by a patient face-to-face interview.

Results: Out of 102 patients, females (57.84\%) patients were more prevalent than men with the age group of 50-59 y in both groups. Methotrexate was most commonly prescribed drug in group 1(36.5\%), whereas in group 2 are Sulfasalazine (37\%). Among the DMARDs unit cost of methotrexate is high but the monthly cost was high for Sulfasalazine, because the methotrexate is prescribed on a once-weekly basis while sulfasalazine is taken twice a day. The cost of NSAIDs comes around $46.47 \%$ of the total drug cost of the month. In steroids, cost comes around $11.73 \%$ of the total drug cost. Among the direct cost of two groups, the drug cost and transportation cost is higher when compared with other costs. Indirect costs such as lost wages, due to disease is higher in group 1.

Conclusion: The study concluded that the burden of RA to the patient is huge, Appropriate standard prescribing guidelines should be developed and implementation of the rational drug must be promoted. Polypharmacy was reported in group 1 hospital, the progression of symptoms was the same in both hospitals, it increases the cost of therapy and overall cost of patients. Hence it becomes vital to diagnose and control the disease at an early stage to control the economic burden on the patient.

Keywords: Rheumatoid arthritis, DMARDs, Cost of illness, Comparison of prescribing pattern of two groups

(C) 2020 The Authors. Published by Innovare Academic Sciences Pvt Ltd. This is an open access article under the CC BY license (http://creativecommons.org/licenses/by/4.0/) DOI: http://dx.doi.org/10.22159/ijpps.2020v12i2.35935. Journal homepage: https://innovareacademics.in/journals/index.php/ijpps

\section{INTRODUCTION}

Rheumatoid arthritis is an autoimmune disorder that causes joint pain and damage throughout the body. It mainly affects joints, connective tissues, muscles, tendons and fibrous tissues (WHO definition). Uncontrolled inflammatory reaction of the disease may lead to joint damage, functional disability, decreased quality of life and increased mortality. Autoimmune disease is an illness that occurs when the body tissue mistakenly attacks normal healthy cells. The abnormal immune response causes inflammation and thickening of the membrane (synovium) that lines the joints. Inflammation of the synovium is called synovitis [1].

The worldwide annual incidence of RA is approximately 3 cases per 10,000 populations and the prevalence rate is estimated at around $1 \%$ affecting women two to three times more than men. It is reported that in India, the prevalence of RA is $0.75 \%$. This indicates that in India there are more than one crore patients affected by this devastating disease [2]

The main aim of the treatment of RA is relieving pain, reducing joint swelling slowing or preventing joint damage, improving the physical function and wellbeing. The drugs used for RA include DiseaseModifying Anti-Rheumatic drugs (DMARDs), Non-Steroidal Antiinflammatory Drugs (NSAIDs), Biological Agents and Corticosteroids [1]. Nonpharmacological treatments include physical therapy, modified exercise programs and devices that ease physical stress on the joints. People with RA are also encouraged to make lifestyle changes such as balancing activity with rest, eating a healthy diet and reducing emotional stress [2].

Pharmacoeconomics is defined as the branch of health economics which deals with the measurement of both the costs and consequences. Generally, the cost can be categorized into 3 categories-direct cost, indirect cost and intangible cost. Direct medical cost covers direct medical cost and direct non-medical cost. Direct medical cost includes the cost of the consultation, hospitalization cost, medical staff cost, administrative cost, diagnostic tests and procedures and medication cost. Direct nonmedical costs include food cost and transportation cost. Indirect cost is due to lost productivity including an absence of duties, sick leaves, early retirement etc. Intangible costs are defined as pain and suffering of a patient which are excluded from the study. Pharmacoeconomics deals with cost and outcome of therapy. The outcome in RA has been described in different studies, mainly in terms of mortality, radiographic changes and functional disability scores. The most important factors affected by patients are pain or stiffness in joints and increasing economic loss depending on ability and loss of or changes in employment during the course of RA [3].

\section{MATERIALS AND METHODS}

\section{Study design and ethical considerations}

This was an observational study conducted in the inpatient and outpatient departments of two different tertiary care hospitals in Salem obtaining approval of the Institutional Ethics Committee (IEC) (Registration Number EC/PHARM D/2019.06). 102 patients were enrolled in the study. This study was conducted for a period of $6 \mathrm{mo}$ from February 2019 to July 2019. Patients who met the inclusion criteria were enrolled in the study. All information relevant to the study was collected from case records. The sociodemographic characters such as age, gender, marital status, employment status, education status and disease duration were collected by patient face to face interview. The cost of medicines was obtained from the bill of pharmacy from where they purchase medicines so that the cost to 
patients can be measured. In addition, the cost of the diagnostic tests was obtained from the laboratory of the hospital. The indirect costs such as productivity loss of patient and productivity loss of family were calculated. All the costs were added up for each patient and for all patients to obtain the total. Patients above $18 \mathrm{y}$ and patient on stable therapy with RA more than 3 mo are included in this study.

\section{Data analysis and interpretations}

The study subjects were described in respect of their demographic profiles according to their age and gender. The continuous variables of both groups were analyzed and interpreted by the student " $\mathrm{T}$ " test. The categorical variables of them were analyzed and interpreted by the $\chi^{2}$ (Chi-square) test. The above statistical procedures were undertaken with the help of the statistical package namely IBM SPSS Statistics-20. The P-values less than or equal to $0.05(\mathrm{P} \leq 0.05)$ was fixed as the level of significance.

\section{RESULTS}

A total of 102 were enrolled in the study ( 52 from group 1 hospital and 50 from group 2 hospital). Among them, 59 females and 53 male patients. The percentage of females was $57.84 \%$ and those of males were $51.96 \%$. Majority of people belong to the age group of 50-59 y in both groups $25 \%$ and $42 \%$ respectively. This was followed by daily wages $(7.2 \%)$, professionals $(6.2 \%)$, Student $(2 \%)$, Patient retired from the service (1\%). and whereas in group 2$24(12 \%)$ patient's population consist of daily wages, followed by housewives (8\%), Professionals (2.5\%), Business (2. 5\%). Duration of the disease extends from over less than one year to more than 20 $y$. Both group patients had less time span (0-2 y). In group $148.07 \%$ and group $280 \%$ of the patients had the disease duration of $0-2 \mathrm{y}$. In group $120(38.46 \%)$ patients had disease duration of 3-5 y and in group is $16 \%$. Only $5.76 \%$ of the patients had the disease for about $6-8$ y in group 1 , whereas in group 2 is $2 \%$. In group $17.46 \%$ of the patient had the disease duration of $9-11 \mathrm{y}$, whereas in group 2 is $2 \%$.

During the current treatment, all the patients were prescribed with DMARDs which is the first line drug for RA. Methotrexate is highly prescribed drug in group $1(36.5 \%)$, Sulfasalazine is highly prescribed drug in group $2(37 \%)$. Other drug such as Hydroxychloroquine $21.5 \%$ in group 1 , whereas in group 2 is $6 \%$ $7.46 \%$ of Leflunomide is used in group 1 only. Most frequently used combination of the drug was 2 DMARDs i.e., Methotrexate+Sulfasalazine, $11.5 \%$ in group 1 and group 2 is $4 \%$. Other drugs such as Methotrexate+Hydroxychloroquine $9.61 \%$ in group 1 and group 2 is $10 \%$ in table 1.

Table 1: Total number of patients taking DMARDs

\begin{tabular}{lll}
\hline Dmadrs & No. of patient involved & \\
\cline { 2 - 3 } & Group 1 & Group 2 \\
\hline Methotrexate & $19(36.5 \%)$ & $10(20 \%)$ \\
Hydroxychloroquine & $11(21.5 \%)$ & $3(6 \%)$ \\
Sulfasalazine & $4(7.69 \%)$ & $37(74 \%)$ \\
Leflunomide & $4(7.69)$ & 0 \\
Methotrexate+Sulfasalazine & $6(11.53)$ & $2(4 \%)$ \\
Methotrexate+Hydroxychloroquine & $5(9.61 \%)$ & $5(10 \%)$ \\
Methotrexate+Leflunomide & $1(1.92 \%)$ & 0 \\
Hydroxychloroquine+Sulfasalazine & 0 & $5(10 \%)$ \\
Methotrexate+Hydroxychloroquine+Leflunomide & $6(11.53 \%)$ & 0 \\
Methotrexate+Hydroxychloroquine+Sulfasalazine & $2(3.84 \%)$ & 0 \\
\hline
\end{tabular}

Among DMARDs, the unit cost of Methotrexate $(0.17 \%)$ was high when compared with other DMARDs in group 1 , but the monthly cost of leflunomide was high. Leflunomide consumes about $0.75 \%$ of drug cost per month followed by Hydroxychloroquine $0.26 \%$ and Sulfasalazine $0.56 \%$.

In biological agent, Rituximab (50.4\%) cost was high when compared with other biological agent. The cost of NSAIDs comes around $2.36 \%$ of the total drug cost of month. In steroids cost comes around $0.59 \%$ of the total drug cost

Table 2: Total drug cost per month in group 1 and group 2

\begin{tabular}{|c|c|c|c|c|c|c|}
\hline \multirow[t]{2}{*}{ Drugs } & \multicolumn{3}{|c|}{ Group 1} & \multicolumn{3}{|c|}{ Group 2} \\
\hline & $\begin{array}{l}\text { Unit } \\
\text { price }\end{array}$ & Cost of drug/month & \% Drug cost & $\begin{array}{l}\text { Unit } \\
\text { price }\end{array}$ & $\begin{array}{l}\text { Cost of } \\
\text { drug/month }\end{array}$ & \% Drug cost \\
\hline \multicolumn{7}{|l|}{ DMARDs } \\
\hline Methotrexate & 32 & 128 & 0.17 & 11 & 88 & 7.05 \\
\hline Hydroxychloroquine & 6.23 & 186.9 & 0.26 & 6.47 & 194.1 & 15.5 \\
\hline Sulfasalazine & 18 & 540 & 0.75 & 5.47 & 328 & 25 \\
\hline Leflunomide & 5.47 & 328 & 0.56 & 0 & 0 & 0 \\
\hline \multicolumn{7}{|l|}{ Biological agent } \\
\hline Adalimumab & 25000 & 25000 & 35 & 0 & 0 & 0 \\
\hline Etanercept & 7000 & 7000 & 9.81 & 0 & 0 & 0 \\
\hline Rituximab & 36000 & 36000 & 50.4 & 0 & 0 & 0 \\
\hline \multicolumn{7}{|l|}{ NSAIDs } \\
\hline Bromelain+Trypsin+RutosideTrihydrate & 17.1 & 1026 & 1.43 & 0 & 0 & 0 \\
\hline Piroxicam & 13 & 585 & 0.82 & 7.50 & 225 & 18 \\
\hline Diclofenac gel & 79 & 79 & 0.11 & 72 & 72 & 5.5 \\
\hline \multicolumn{7}{|l|}{ STEROIDS } \\
\hline Triamcinolone acetonide & 6.7 & 201 & 0.28 & 0 & 0 & 0 \\
\hline Deflazacort & 7.5 & 225 & 0.31 & 8.90 & 267 & 21.3 \\
\hline
\end{tabular}

Among DMARDs, the total cost of Sulfasalazine (25\%) was high when compared with other DMARDs. Hydroxychloroquine consumes about $15.5 \%$ and Methotrexate (7.05\%). In Group 2 there is no biological agent taken, the cost of NSAIDs comes around 32\% of the total drug cost of month. Steroids come around $21.3 \%$ of the total drug cost. The direct medical cost was higher in group 1 in both reviews. 
Table 3: Comparison of direct medical costs between the two groups at R1 and R2

\begin{tabular}{|c|c|c|c|c|c|c|c|}
\hline \multirow[t]{2}{*}{ COST } & \multicolumn{2}{|c|}{ Group 1 (Review 1) } & \multicolumn{4}{|c|}{ Group 2 (Review 1) } & \multirow[t]{2}{*}{ Significance } \\
\hline & Mean & SD & $\%$ Cost & Mean & SD & \% Cost & \\
\hline Drug & 4642.61 & 791.58 & 31.84 & 1433.24 & 1009.01 & 16.66 & $\mathrm{P}=0.005$ \\
\hline Consultation & 590.38 & 517.63 & 3.54 & 225.00 & 61.65 & 2.61 & $\mathrm{P}<0.001$ \\
\hline Lab Cost & 1767.31 & 3398.96 & 12.12 & 810.00 & 423.90 & 9.41 & $P=0.051$ \\
\hline Radiology cost & 438.46 & 334.98 & 4.0 & 523.00 & 204.34 & 6.08 & $P=0.129$ \\
\hline Surgical & 6634.61 & 21956.31 & 45.51 & 5300 & 29561.5 & 61.62 & $P=0.067$ \\
\hline Hospital & 505.19 & 723.26 & 3.46 & 308.94 & 293.25 & 3.59 & $\mathrm{P}<0.001$ \\
\hline Total Direct cost & 14577.88 & $27,722,72$ & 100 & 8600.18 & $32,379.27$ & 100 & $\mathrm{P}=0.4297$ \\
\hline
\end{tabular}

Table 4: Comparison of direct non-medical cost between two groups

\begin{tabular}{|c|c|c|c|c|c|c|c|c|}
\hline \multirow[t]{2}{*}{ Cost } & \multirow[t]{2}{*}{ Review } & \multicolumn{3}{|c|}{ Group 1} & \multicolumn{3}{|c|}{ Group 2} & \multirow[t]{2}{*}{ Significance } \\
\hline & & Mean & SD & $\%$ Cost & Mean & SD & $\%$ Cost & \\
\hline \multirow[t]{2}{*}{ Transport } & R1 & 374.23 & 418.74 & 56.14 & 285.76 & 176.49 & 64.58 & $\mathrm{P}=0.171$ \\
\hline & $\mathrm{R} 2$ & 343.3 & 439.69 & 59.5 & 181.00 & 122.96 & 68.5 & $P=0.035$ \\
\hline \multirow[t]{2}{*}{ Food } & $\mathrm{R} 1$ & 292.30 & 301.85 & 43.85 & 156.72 & 187.40 & 35.41 & $P=0.008$ \\
\hline & $\mathrm{R} 2$ & 233.08 & 249.09 & 40.43 & 83.0 & 39.29 & 31.4 & $\mathrm{P}<0.001$ \\
\hline \multirow[t]{2}{*}{ Total } & $\mathrm{R} 1$ & 666.53 & 720.85 & 100 & 442.48 & 357.89 & 100 & $P=0.0246$ \\
\hline & $\mathrm{R} 2$ & 576.38 & 688.78 & 100 & 264 & 162.25 & 100 & $\mathrm{P}=0.0012$ \\
\hline
\end{tabular}

Table 5: Comparison of indirect cost between the two groups at R1 and R2

\begin{tabular}{|c|c|c|c|c|c|c|c|c|}
\hline \multirow[t]{2}{*}{ Cost } & \multirow[t]{2}{*}{ Review } & \multicolumn{3}{|c|}{ Group 1} & \multicolumn{3}{|c|}{ Group 2} & \multirow[t]{2}{*}{ Significance } \\
\hline & & Mean & SD & $\%$ Cost & Mean & SD & $\%$ Cost & \\
\hline \multirow[t]{2}{*}{ Self-production } & R1 & 447.11 & 619.64 & 46.43 & 386.0 & 437.76 & 76.79 & $P=0.568$ \\
\hline & $\mathrm{R} 2$ & 434.61 & 621.78 & 31.1 & 276.00 & 306.43 & 69.34 & $P=0.108$ \\
\hline \multirow[t]{2}{*}{ Family product loss } & $\mathrm{R} 1$ & 515.38 & 553.91 & 53.54 & 205.00 & 305.58 & 24.68 & $P=0.001$ \\
\hline & $\mathrm{R} 2$ & 453.85 & 554.03 & 32.48 & 122.0 & 177.61 & 44.62 & $\mathrm{P}<0.001$ \\
\hline \multirow[t]{2}{*}{ Indirect cost } & $\mathrm{R} 1$ & 962.49 & 1173.55 & 100 & 591 & 743.34 & 100 & $P=0.0293$ \\
\hline & $\mathrm{R} 2$ & 1397 & 1175.81 & 100 & 398 & 484.61 & 100 & $\mathrm{P}=<0.0001$ \\
\hline
\end{tabular}

\section{DISCUSSION}

102 patients were enrolled in the study. Female patients $(57.84 \%)$ were more prevalent than male patients $(42.17 \%)$. Similar prevalence was found in studies carried out by Vidhya Alex et al $(82.5 \%)$ [2] and There were 628 females and 161 male [10], Nagappa AN et al., [8], female to male ratio is3:1. The age group distribution in both groups between $50-59$ y constitutes with $25 \%$ and $42 \%$, which is the highest percentage, whereas the study conducted by Vidhya Alex et al., [2], reports that mean age was $52.6 \pm 10.89$, mean age is $40.57 \pm 13.69$. The majority of the patients were married category in both groups (90.4\%) and (84.0\%), whereas the study conducted by Vidhya Alex et al., [2] with mean age $47.6 \hat{\mathrm{A}} \pm 12.6$ and $47.1 \hat{\mathrm{A}} \pm 14.4$ y respectively [3]. reports that $(90 \%)$ of the patient belong to married category. The educational status of the patient in group-1 is primary category $(32.7 \%)$ and in group-2 is secondary category (70\%), similar results were reported in Vidhya Alex et al., [5], that majority of the patients in secondary category (34\%). Occupational status shows that $21 \%$ of the patient population consist of house wives in group 1 . This was followed by daily wages $(7.2 \%)$, professionals $(6.2 \%)$, Student $(2 \%)$, Patient retired from the service $(1 \%)$. and whereas in group $2-24(12 \%)$ patient population consists of daily wages, followed by housewives (8\%), Professionals (2.5\%), Business $(2.5 \%)$. While a study conducted by Vidhya Alex et al., [5], shows the majority of the population consists of housewives $(66 \%)$, followed by $(10 \%)$, patients who retired from their services $(7.5 \%)$, patients who worked for daily wages $(6.5 \%)$, patients with desk jobs (3\%)and the unemployed population consists of (2\%) of the study population.

In this study, Methotrexate were highly used in Group-1(36.5\%), whereas in Group-2 is Sulfasalazine (74\%). Other studies such as Vidhya Alex et al.,[2], Peter Tug well et al. [4], in the USA and Canada reported that highly used drug is In this study, Methotrexate were highly used in Group-1(36.5\%), whereas in Group-2 is Sulfasalazine $(74 \%)$ show sthat Methotrexate+Hydroxy chloroquine a highly prescribed drug. In this study NSAID-Bromelain+Trypsin+Rutoside
Trihydrate (40.38\%) is highly prescribed in Group1 and in Group 2 Piroxicam $(88 \%)$ is a highly prescribed drug. The other study such as Vidhya Alex et al., [2], reported that the frequently used NSAID has been Etoricoxib (6.5\%), G In this study, Methotrexate were highly used in Group-1(36.5\%), whereas in Group-2 is Sulfasalazine (74\%). Other studies such as Vidhya Alex et al., [2], and Nyi Mekar also repoted there are $20.81 \%$ of patients were given MTX, $4.17 \%$ [5]. Peter Tug well et al. [4] in the USA and Canada reported that highly used drug is In this study, Methotrexate were highly used in Group-1(36.5\%), whereas in Group-2 is Sulfasalazine (74\%). reported that Indomethacin (77\%) is highly prescribed drug. The biological agents such as Adalimumab (3.8\%), Etanercept (5.8\%) and Rituximab $(1.9 \%)$ were present in the RA group only. No biological agents were present in the ortho group. Another study such as Kowalik et al.2018, reported that Adalimumab (21\%), Etanercept $(37 \%)$ is a highly prescribed drug. In our study Triamcinolone Acetonide (19.2\%) is highly prescribed in group 1 and group 2 Deflazacort (28\%) is highly prescribed, whereas the study conducted by Vidhya Alex et al., [2], reports that Deflazacort is a highly prescribed steroid, Gawde et al., [6reports that Prednisolone $(n=22)$ is used in the study. Folic acid tablets were used in both groups $69.2 \%$ and $24 \%$. Calcium tablets were used in both groups $28.8 \%$ and $62 \%$ and Multivitamin tablets also used in both groups $46.15 \%$ and $54 \%$. Other drugs such as anti-ulcer drugs $(113.4 \%)$ in RA group and $94 \%$ in ortho group, In RA group anti emetics (58\%) were used and ortho group $10 \%$ were used those drugs. Other studies such as Vidhya Alex et al., [2], reveals that Diclofenac gel (2.5\%), Calcium and Multivitamin tablet $(51.5 \%)$ is commonly prescribed. Gwade et al.,[6], reports that Calcium supplements $(n=69)$ are commonly prescribed.

Among DMARDs, the unit cost of Methotrexate $(0.17 \%)$ was high when compared with other DMARDs in group 1, but the monthly cost of leflunomide was high. Leflunomide consumes about $0.75 \%$ of drug cost per month followed by Hydroxychloroquine $0.26 \%$ and Sulfasalazine $0.56 \%$. In biological agents, Rituximab (50.4) cost was high when compared with other biological agents. The cost of NSAIDs 
comes around $2.36 \%$ of the total drug cost of month. In steroids, the cost comes around $0.59 \%$ of the total drug cost. In Group 2 among DMARDs, the total cost of Sulfasalazine (25\%) was high when compared with other DMARDs. Hydroxychloroquine consumes about $15.5 \%$ and Methotrexate (7.05\%). In Group 2 there is no biological agent taken, the cost of NSAIDs comes around $32 \%$ of the total drug cost of month. Steroids come around $21.3 \%$ of the total drug cost.

The direct medical cost was higher when compared with group2. Direct cost includes the cost of medicines, consultation costs, laboratory costs, radiological cost, surgical and hospital costs. Among them, drug cost is higher. Vidhya Alex et al. [2], Nagappan et al., [7], shows similar reports. Among the direct non-medical costs, transportation and food cost is higher than group 2. The indirect cost are higher when compared with group 2 . Indirect cost components include productivity loss of patience and productivity loss of family.

The average cost is higher in group 1 due to direct and indirect costs. There are less pharmacoeconomic studies conducted in India in the area of RA. In a study conducted by Vidhya Alex et al., [2], the average cost of illness of patients with RA was estimated to be $2229.99 /$ month. In detail direct cost accounted for 86.545 of the total cost, slightly higher than indirect cost. Out of which $38.21 \%$ was consumed by the cost of medicine, Laboratory tests were covered by about $15.31 \%$, consultation cost $6.34 \%$, transportation and food cost $23.75 \%$, the same result observed. In societal cost analysis of RA in China conducted by Chuanhui et al., [8], shows indirect cost covers $10 \%$ of the total cost of illness. In a study conducted in India by Sukhpreet et al.,[9], estimated the average total cost was $999 \pm 76$ per/month, the average monthly direct cost of RA was estimated to be $623 \pm 31$, the average indirect cost was found to be $368 \pm 62$ per month.

The treatment cost differs in different countries. In the UK, the average annual medical cost was reported to range from $€ 3575$ to $£$ 3638 in a study by $\mathrm{N}$ J Cooper et al., [10]. The out of pocket expenditure in Germany was found to be $£ 417.20$ per year which accounted for $15.3 \%$ of total direct costs. The Gross Domestic Product in UK was 41,220 US dollars in 2000. RA patients in UK spend only $7.61 \%$ of their per capita income for treatment. While in Australia only about $1.79 \%$ of their per capita income is needed for the treatment of RA. Germany per capita GDP income was 42,540 US $\$$ and $0.85 \%$ of per capita income is spending on the treatment of RA. The result of the US-based study showed the mean total annual direct medical cost for RA patient was $\$ 9,519$ in 2001. Medicine cost was $\$ 6,324(66 \%$ of the total), while hospitalization cost was only $\$ 1,573(17 \%)$. Approximately $25 \%$ of patients received biological therapy. The mean total annual direct cost for the patient who was not taking biological was $\$ 6,164$. Per month cost was calculated as $\$ 513.66$. This is higher than our direct cost which is about $\$ 35.95$ per month. The discrepancy of annual cost of RA might be due to the difference in health care systems, referral practices, financing, GDP, and methodologies of studies between India and other countries.

\section{CONCLUSION}

The study concluded that the burden of RA to the patient is huge. Our study helps to improve our knowledge about the burden of RA. Prescribing pattern of RA drugs in both hospitals was compared. Appropriate standard prescribing guidelines should be developed and implementation of the rational drug must be promoted. Polypharmacy was reported in group 1 hospital, the progression of symptoms was the same in both hospitals, it increases the cost of therapy and overall cost of patients. Clinical pharmacists play a major role in reducing the irrationality in the prescription by assisting the prescriber in selecting the correct drug and dose thereby avoiding polypharmacy and improve the patient's quality of life.

\section{LIMITATION}

Study time period was 6 mo. It requires more time to do it in a large population

The study population involved in the study was less.

\section{ABBREVIATION}

RA-Rheumatoid Arthritis, DMARD-Disease-Modifying AntiRheumatoid Drugs, RF-Rheumatoid Factor, ESR-Erythrocyte Sedimentation Rate, CRP-Couple Reactive Protein

\section{ACKNOWLEDGMENT}

We heartily thank Dr. N. Senthil Kumar (Principal) Annai JKK Sampoorani Ammal College of Pharmacy, Komarapalayam for providing their immense support throughout the study.

\section{FUNDING}

Nil

\section{AUTHORS CONTRIBUTIONS}

All authors have contributed equally in this piece of work.

\section{CONFLICT OF INTERESTS}

The authors declare no conflicts of interest with respect to the authorship and or publication of this article.

\section{REFERENCES}

1. Roger Walker, Cate Whittlesea. Clinical pharmacy and therapeutic. $5^{\text {th }}$ Edition; 2012.

2. Vidya Alex, Sumitha Cheruvallikattil, Suja Abraham, Bincy Varghese. Cost of illness of rheumatoid arthritis in south India. World J Pharm Res 2015;11:1305-16.

3. Kashefi, Saeid, Sang Min Lee, Surulivelrajan Mallaysamy, Girish Thunga P. Demographic, clinical characteristics and drug prescription pattern in patients with rheumatoid arthritis in south indian tertiary care hospital. Int J Pharm Pharm Sci 2016;8:251-7.

4. Tugwell P. Pharmacoeconomics of drug therapy for rheumatoid arthritis. Rheumatology (Oxford) 2000;39:43-7.

5. Saptarini, Nyi Mekar, Marlia Singgih Wibowo, Tutus Gusdinar Correlation study of age, disease duration, and erythrocyte sedimentation rate among the indonesian rheumatoid arthritis patients. Int J Pharm Pharm Sci 2015;7:274-7.

6. Gawde SR, Shetty YC, S Merchant, Kulkarni UJ, Nadkar MY. Drug utilization pattern and cost analysis in rheumatoid arthritis patients, a cross-sectional study tertiary care hospital. $\mathrm{Br} \mathrm{J}$ Pharm Res 2013;3:37-45.

7. Nagappa, Khera K, Rau NR. Pharmacoecnomic and healthrelated quality of life in rheumatoid arthritis (RA) patients in tertiary care hospital. Karnataka 2013:A1-A298. Doi:10.1016/j.jval.2013.03.1128

8. Chuanhui XU, Xiuru Wang, Rong MU. Societal cost of rheumatoid arthritis in china: a hospital-based cross-sectional study. Arthritis Care Res 2014;66:523-31.

9. Sukhpreet, Agarwal V, Tiwari P. Treatment and monitoring costs in rheumatoid arthritis: preliminary results from an Indian setting. Indian J Pharm Sci 2007;69:226-31.

10. Cooper NJ. Economic burden of rheumatoid arthritis. A systematic review. Rheumatology 2000;39:28-33. 